\title{
Assessment of SCADA Technology Applications To Automate U.S. Army Water and Wastewater Sanitary Systems
}

by Richard J. Scholze and Hany H. Zaghloul

November 2001 


\section{Foreword}

This study was conducted for the Directorate of Military Programs, Headquarters, U.S. Army Corps of Engineers (HQUSACE), under Project 622720A896, "Base Facilities Environmental Quality (6.2 Exploratory Development)," Work Unit TF0, "Stormwater/Wastewater Technology." Thetechnical monitor was Robert Fenlason, CEMP-RI.

The work was performed by theE nvironmental Processes Branch (CN-E) of the Installations Division (CN), Construction Engineering Research Laboratory (CERL). TheCERL principal investigator was RichardJ . Scholze. MichelleH ansen is Acting Chief, CN-E, and Dr. J ohn T. Bandy is Chief, CN. The technical editor was Linda Wheatley, I nformati on Technol ogy Laboratory - Champaign. Theassociated Technical Director was Gary W. Schanche. The Director of CE RL is Dr. Alan W. Moore.

CERL is an element of the Engineer Research and Development Center (ERDC), U.S. Army Corps of Engineers. The Commander and Executive Director of ERDC is COL J ohn Morris III, EN, and the Director of ERDC is Dr. J ames R. Houston. 


\section{Contents}

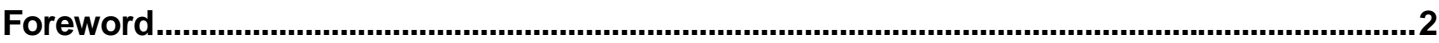

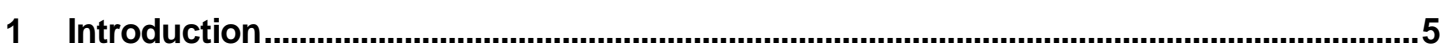

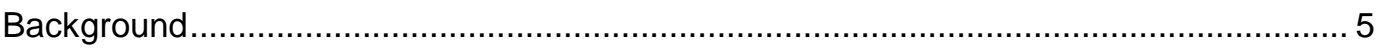

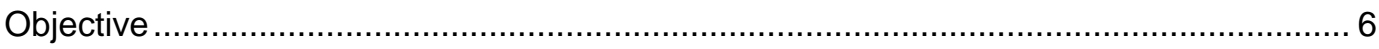

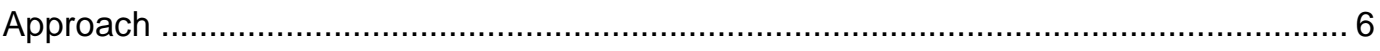

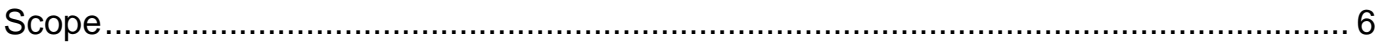

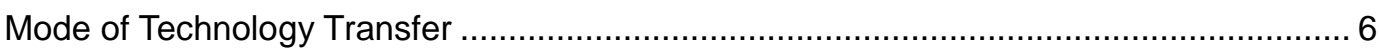

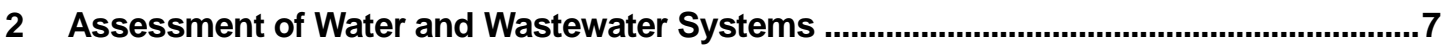

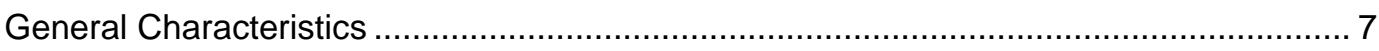

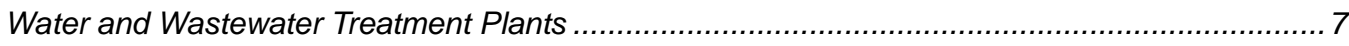

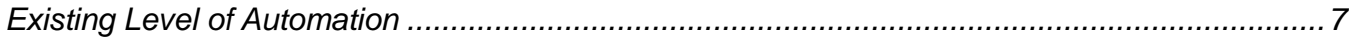

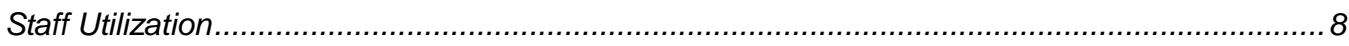

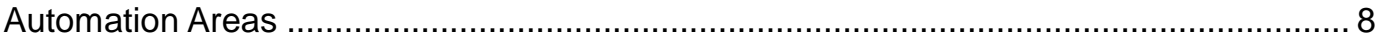

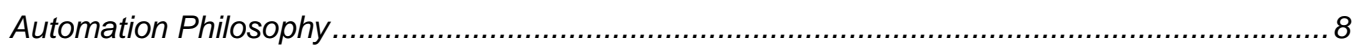

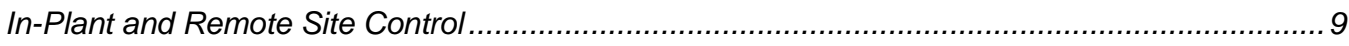

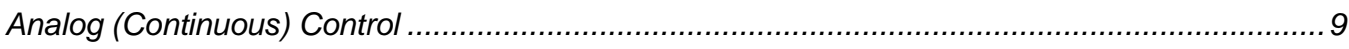

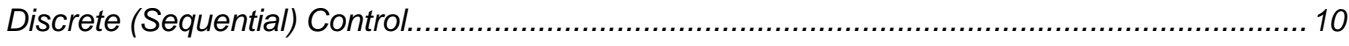

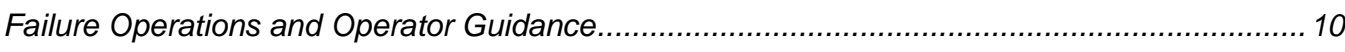

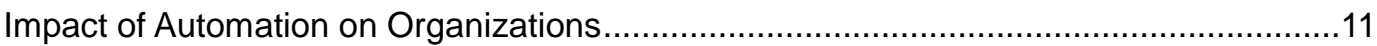

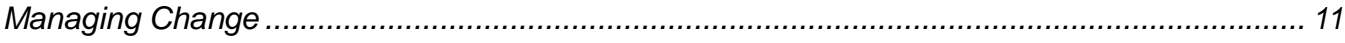

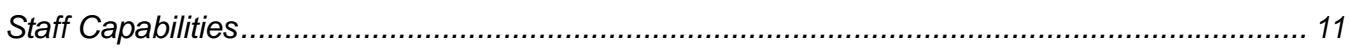

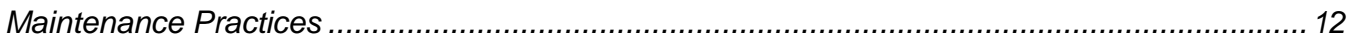

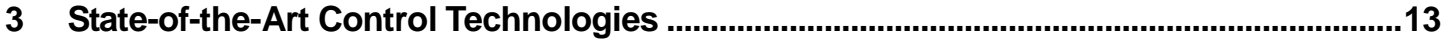

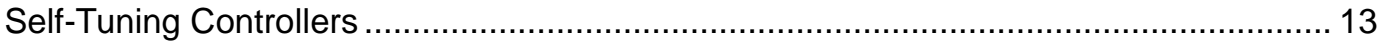

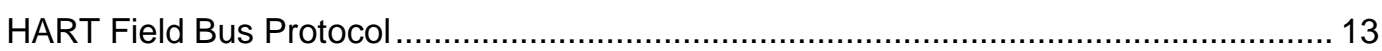

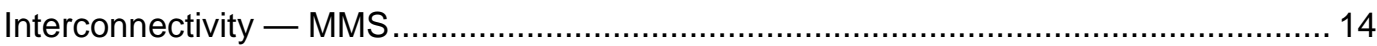

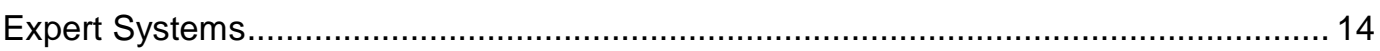

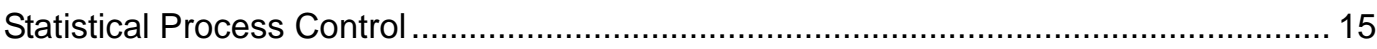




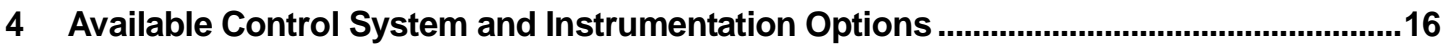

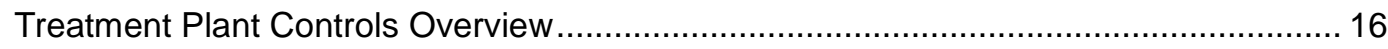

Distribution System and Booster Pump Control Overview ............................................. 16

Distribution System Elevated Tanks Monitoring Overview ........................................... 17

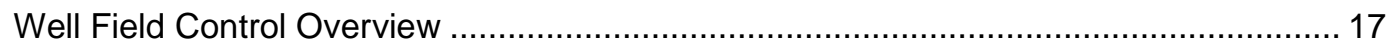

5 Advanced Technologies for Control Systems Communication .......................................18

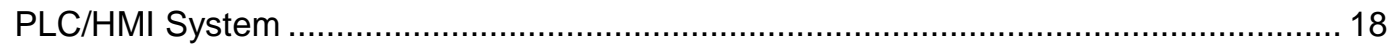

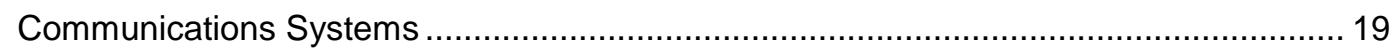

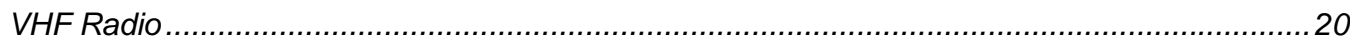

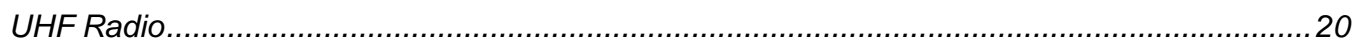

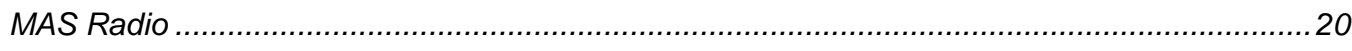

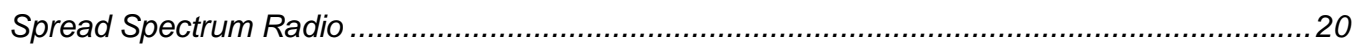

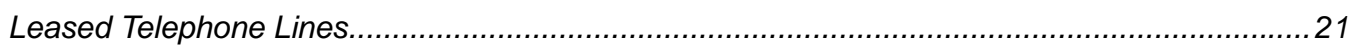

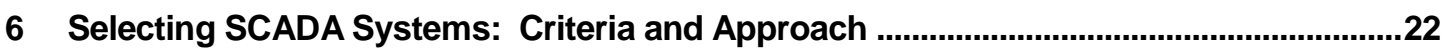

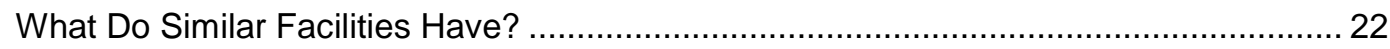

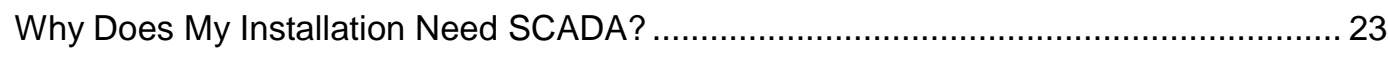

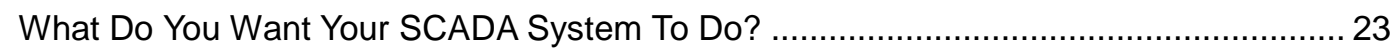

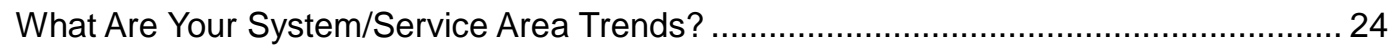

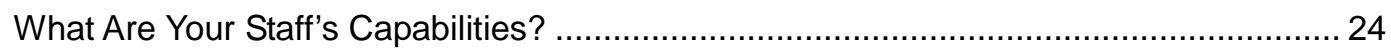

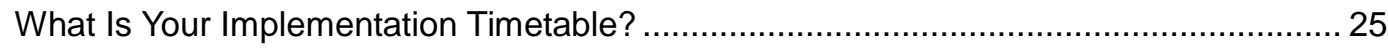

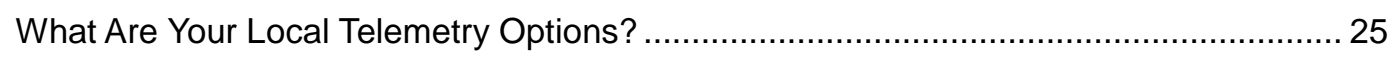

What Are Your Budget and Expense Constraints? .................................................... 25

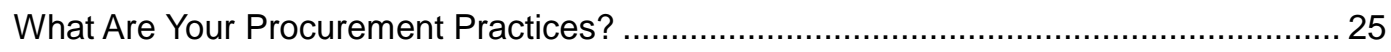

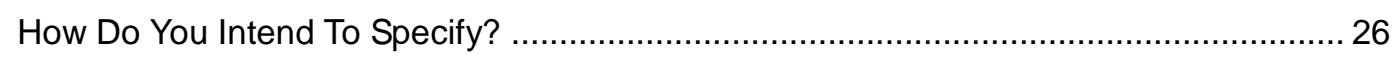

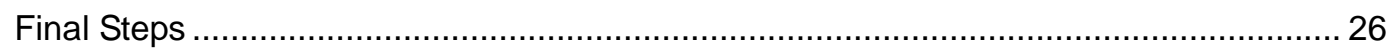

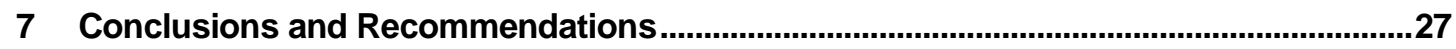

References ….......................................................................................................................28

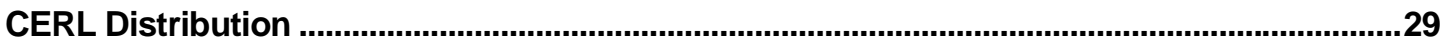

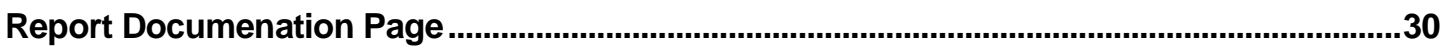




\section{Introduction}

\section{Background}

The U.S. Army operates more than 100 small wastewater treatment plants (WWTPs), of which 75 percent use trickling filters, 15 percent use an activated sludge process, and 10 percent use other treatment methods. Army WWTPs range in capacity from 0.003 to 8 million gallons per day (MGD), with an average capacity of about 1.0 MGD. The physical size and complexity of Army WWTPs generally parall el the systems' treatment and distribution capacities (i.e., larger capacity systems are bigger and more complex than relatively smaller capacity systems).

As in many other areas, theArmy is facing reductions in budget and personnel that support and operate its domestic and industrial water and wastewater systems. One way to maintain required levels of service despite such cuts is to increase efficiency by using automated systems at both drinking water and wastewater treatment plants. Many different automation technologies have already been successfully applied at municipal and industrial water and wastewater treatment plants, and collection and distribution systems. TheArmy, however, has automated relatively few of its water and wastewater systems, even though the technology to do so is both economically practical and immediately available. Simple control automation that uses durable equipment offers theArmy a promising alternativeto labor-intensive operations, especially in light of theArmy's shortage of skilled workers. The installation and use of simple, reliable automated controls can makeplant operations more cost-effective by using the available workforce more effectively and by reducing the use of energy and chemicals. The Army can expect to gain substantial savings by appropriate automation at its more than 100 facilities.

The first step in beginning to automateArmy water and wastewater systems was to review and evaluate the systems, their needs, and available automation technologies. This report complements the findings of a 2-yr study focused on selected water and wastewater systems as a part of a water and wastewater automation project previously conducted by the Construction Engineering Research Laboratory (CERL) and published in USACE RL Technical Report EP-94/01, An Evaluation of Technologies To AutomateU.S. Army Water and Wastewater Systems, November 1993. 


\section{Objective}

The objective of this research was to providea state-of-the-art assessment for water and wastewater systems automation.

\section{Approach}

Interviews were conducted with architectural and engineering (AE) firms and consultants from different national regions to review their Supervisory Control and Data Acquisition (SCADA) recommendations, and to assess the current state of automation and identify areas where automation would be cost beneficial. A literature search was performed to identify appropriate technologies that might be applied to the identified processes. Criteria were derived to rate each technology for its potential for successful application to Army water and wastewater plants. The technol ogies that best met the criteria were recommended, and selection criteria for implementing those technologies were outlined.

\section{Scope}

This study assessed automation technology that may be applied in any Army facility. In reviewing automation techniques available for Army water and wastewater treatment plant operation and distribution/collection systems, the focus was on the 2 to 5 MGD plants, commonly found at larger installations and the most feasible candidates for automation. The assessment of various new technol ogies and options included analysis of comparative features and discussion of their potential impact on the current mode of operations within typical Army water or wastewater treatment plants. Emphasis was given to automated systems maintenancerequirements as a driver for implementation cost in system overall life-cycle cost analysis considerations. Recommendations for automation technology implementation schemes and prioritization of technol ogy bundles to be considered for Army needs area major focus.

\section{Mode of Technology Transfer}

It is anticipated that the results of this study will be incorporated into a Public Works Technical Bulletin (PWTB). 


\section{Assessment of Water and Wastewater Systems}

\section{General Characteristics}

The foll owing chapter is a general description of typical Army water and wastewater treatment facilities. The plant's layout and characteristics of the facilities briefly discussed bel ow were based on the findings of a 2-yr study focused on selected water and wastewater systems that was conducted in the early 1990s for Army sanitary facilities (Kim and Skrentner 1993). The information was reviewed and found to be still applicable.

\section{Water and Wastewater Treatment Plants}

The Army uses several different processes for its domestic wastewater treatment plants. Most facilities use trickling filters, while some use an activated sludge process. Industrial wastewater plants use predominantly chemical treatment processes. In contrast, all of the water plants visited use the same processes - flocculation and sedimentation followed by filtration and chlorination.

Most of the facilities are more than 20 years old. Older facilities will cost more to automate, since most manual control valves will need to be replaced with electrically or pneumatically operated valves. For pumps and motors, electrical work must meet current codes, and old equipment must be updated. This will also affect costs.

Life-cyde costs often make automation less attractive in smaller plants. The installed cost of analytical instruments such as pH, dissolved oxygen, and suspended solids remains constant regardless of the application. Thus, whileautomation will reduce chemical costs by the same percentage in a large and a small plant, the total cost saving at the small plant is much less.

\section{Existing Level of Automation}

Kim and Skrentner (1993) found many of the facilities contained some automation. The Fort Gordon, GA, water treatment plant, for example, was about 75 percent 
automated using single-loop controller technology. The Red River Army Depot, TX, water treatment plant automated filter backwashing using programmable logic controllers (PLCs). High-lift pumping was manual, however, because funds to replace the old, manually operated pump isolation valves were insufficient. Many industrial plants have automated individual chemical feed loops. In some plants, however, the automatic loops are no longer used due to the extensive maintenance re quired to keep control valves and $\mathrm{pH}$ probes operating.

\section{Staff Utilization}

None of the plants had completely centralized monitoring of either the plant or the associated collection or distribution system. Several plants had control panels that showed portions of the plant operation. Most of the water plants displayed elevated tank levels at the plant, but little other information on the status of the system. Wastewater lift station monitoring was practically nonexistent. As a result, operators had to make rounds once or twice per shift to take readings, record information, and make process adjustments. This check of the collection and distribution systems is very time-consuming.

Many smaller plants were staffed on off-shifts. Plants at several sites were unmanned during off-shifts, and several of the trickling filter plants were totally unmanned. Operators from other facilities made rounds.

\section{Automation Areas}

\section{Automation Philosophy}

Operation and maintenance capabilities play a major rolein realistically identifying automation needs. The plants are small and, in general, cannot afford sophisticated maintenance staff, equipment, and repair facilities. Operations and maintenance staff has been reduced to the lowest level ever at most plants, even where additional plant processes are being added and operator responsibilities are increasing.

The first step in identifying automation areas was to look at processes that use the greatest percentage of energy or chemicals. Next, labor-intensive processes were examined. Areas where the quality of the effluent could beimproved wereexplored, and finally future optimization areas were identified (Kim et al. 1991).

All of the sites visited had the following common automation needs:

- A combination of in-plant control and control/monitoring of remote sites

- A combination of analog control and discrete control 
- A need for automation to include failure operations and operator guidance.

\section{In-Plant and Remote Site Control}

Operators at most facilities spent from $2 \mathrm{hr}$ per day to $4 \mathrm{hr}$ per shift making rounds to remote sites. These sites included water wells, ground water treatment wells, water reservoirs and altitude valves, swimming pools, wastewater lift and pump stations, and outfalls.

At industrial plants, operators expressed the need to monitor conditions at the industrial processes to detect changes in wastewater characteristics. Remotemonitoring of $\mathrm{pH}$ was the most common need.

\section{Analog (Continuous) Control}

Analog control is characterized by variables that can be continuously observed and represented. For most water and wastewater plants, variables are represented by 4 to $20 \mathrm{~mA}$ or 3 to 15 psig signals.

In an open control loop, continuous measurement of the variableto be controlled is not connected to automatic controls. There is no assurance that the control objective is actually being achieved. Satisfactory control occurs only if the final control el ement is properly set and no disturbances occur. If the original conditions are disturbed, operator intervention is required to maintain balance within the process.

In a closed control loop, continuous measurement of the process variable is routed to a controller. The controller compares this measurement (the feedback signal) with the desired value (the setpoint). If there is any difference between desired and actual values, the controller outputs a corrective action to the final control element. This action is often called feedback control.

A feedforward control loop predicts how much corrective action will be required because of a disturbance. Feedforward control measures one or more inputs to the process. Any change in input causes a corresponding change in the output to the final control element.

Closed-loop control of chemical addition and dissolved oxygen can save minimum of 10 percent in energy and chemical costs compared to open-loop control. For smaller plants with relatively constant effluent quality, feedforward control often provides a similar savings over open-loop control without the need for additional sensors. For example, feedforward controls can pace chlorine addition to plant flow without relying on a chlorine residual analyzer instrument. 


\section{Discrete (Sequential) Control}

Discrete control is characterized by on/off or open/closed-type control actions. These actions are in response to a predefined program of events, elapsed time, or an analog value reaching some preset limit.

Discrete control includes simple on/off control of a single device such as a sump pump, sequential startup/shutdown of a complex device such as a filter press, and a sequence of operations such as a filter backwash operation.

Many water and wastewater processes combine discrete and anal og control. These controls enable security, safety, and optimum performance. Startup and shutdown logic, failure detection, and process characteristic tracking can help minimize dependence on operator-directed corrective actions.

\section{Failure Operations and Operator Guidance}

Most of the site visits were less than a half day for each plant. In this short time interval, several operational problems were observed that could have been prevented with automation.

At one site, the water treatment plant clear well overflowed. It was early afternoon and the el evated tanks were full. In this particular plant, the system should have been near empty rather than completely full at that time of day. Energy and chemicals were being wasted. An automation system would generate a high-level alarm when the clear well was nearly full. At the same time, it could be programmed to recommend the appropriate course of action to the operator (i.e., to stop low-lift pumping). Additionally, the system could be programmed to predict water demand for the day and more closely match production to use.

At another site, an operator had to predict the next day's demand and adjust the plant accordingly. The operator had to walk one-quarter mile to adjust low-lift pumps, then walk back to the office area to adjust all the chemical feed pumps, then adjust the high-lift pumps. Two hours after making these adjustments, the operator discovered that someone had left a filter drain valve open. An automation system would not have placed the filter back in service if the drain valve failed to close. All of the plant adjustments could have been done automatically. 


\section{Impact of Automation on Organizations}

\section{Managing Change}

When new ideas, such as automation, are introduced into an organization, people usually resist. Often the resistance is not so much to the automation itself, but to the way it affects their lives. Change management is a process of following a comprehensive plan to introduce a change through technical and social activities. The technical activities may include installing a sensor or an entireautomation system. The social activities include persuading peopleto adopt the change, training them to use it, and making surethey use it over time. One study reported that 95 percent of the problems in introducing change is due to poor management of the social activities (Skrentner 1988).

People cannot simply be ordered to adopt automation. Although orders hold persuasive force, they are best combined with the planned use of other forces for change. Sound approaches to introducing a complex change, such as automating an entire facility, follow these criteria:

- The sponsors (e.g., sanitation branch chief, utilities division chief, plant supervisors, or operator) of the change know and plan the direction the organization needs to take.

- The change supports going in the direction planned.

- The sponsors understand the nature of the automation change and the effect on its users.

- The sponsors know the level of all involved parties' commitment to the change.

- The sponsors prepare a written plan for managing change.

- The sponsors allow staff to experiment with the change in a nonthreatening environment.

- Staff participates in the change rather than having it imposed from outside.

\section{Staff Capabilities}

Operations staffs at all plants were quite knowledgeable about the operation of the plants and collection/distribution systems. Many of the staff at both the water and wastewater plants each had less than 5 years' experience, however, and, with limited budgets to train these personnel on automated systems, it is more difficult to place new equipment in operation. Emphasis should, therefore, be placed on operations and maintenance manuals and hands-on training by vendors as an integral part of any SCADA training package. 
Even with such training, it takes time for operators and managers to adapt to the change from manual to automatic control. It is better, ther efore, to start with simple control systems. As the plant staff becomes more familiar with automation and instrument maintenance, additional sensors can be added to optimize plant operations. In addition, the staff can test sensors that meet their particular needs.

\section{Maintenance Practices}

Although the scope of this study did not include the operations and maintenance organizations as such, current maintenance practices significantly affect the type of technol ogy recommended. In most plants, mechanical and electrical maintenance was fair to good. Instrumentation and controls maintenance was generally poor. When an instrument or control device broke, control often reverted to manual.

Difficulty in obtaining the right part in a timely manner was a common complaint. The Supply Division is often understaffed and delays occur in obtaining parts. Competitive bidding occasionally results in parts that are not exact replacements. Operation and Maintenance Division (OMD) personnel then have to modify the parts to fit, or trade them with other groups. Even though there is only one supplier, the bidding process must often be foll owed.

The Supply Division is not part of OMD. At some facilities, centralized maintenance staff gave lower priority to the water and wastewater plants.

F or automation to be successful, repairs must be made quickly. Reduced staffs will not have time to control devices manually while waiting for repairs; they will instead revert to control practices that waste energy and chemicals or require overtime. To assure success, automation must balance with existing practices. 


\section{State-of-the-Art Control Technologies}

The technologies listed in this chapter are included for assessing the suitability of off-the-shelf control technologies for Army applications. The incorporation of these options into any current design of SCADA systems has to be implemented by design professionals for control technologies as part of thesystem. Theoverview presented in this chapter is included to introduce readers to various control technology options.

\section{Self-Tuning Controllers}

Self-tuning proportional/integral/derivative (PID) controllers can help achieve optimum control. Self-tuning control is particularly useful in batch applications where process characteristics can vary from batch to batch. Self-tuning is triggered by setpoint changes or on demand. The self-tuning functions measure the process response and derive equivalent process parameters and corresponding optimum PID tuning values. Self-tuning controllers can be used as stand-alonecontrollers, or as a part of a control system. For a PLC-based system, the controller would receive its setpoint from the PLC.

\section{HART Field Bus Protocol}

For years, the standard means to transmit analog signals was 4 to 20 mAdc over twisted-pair wires. With the advent of microprocessor technology, many instrument vendors included this capability in their instruments to improve reliability and accuracy. A natural extension of the technol ogy was to replace the 4 to 20 mAdc output with a digital output. Digital signals are more immuneto noise than are analog signals. In addition, one pair of wires could handle several instruments; sensor maintenance and diagnostics could be performed remotely; and sensor calibration could be performed easily.

Unfortunately, vendors were unable to agree on a standard digital communications protocol. Each vendor had its own proprietary instruments. Recently, the Rosemount Company developed and made publictheir field instrument digital communications protocol. The highway addressable remote transducer (HART) user group 
was formed to support the growing number of companies using smart field instruments. The basic goals of the group are to promote the use of the HART protocol until some other standard is developed, to ensure the interchangeability of devices, and to providean open forum for exchange of information. The Instrument Society of America SP-50 Committee is attempting to develop an international field bus standard as well.

\section{Interconnectivity - MMS}

The Manufacturing Message Specification (MMS) is an internationally accepted standard communications protocol for integrating heterogeneous automation devices. MMS operates on networks based on the Open System Interconnect (OSI) seven-layer stack model. MMS resides in layer seven of the stack and consists of messages that travel across a network. These messages are in a specific format that can be understood by all MMS-compatible devices. Benefits of MMS include:

- better communications among automation devices

- reduced development cost required to add new devices to networks

- lower software maintenance cost

- easier overall Army-wide integration

- smaller vendors are enabled to create innovative products.

MMS is endorsed by major companies such as Allen-Bradley, AEG/Modicon, BurrBrown, Cincinnati Milacron, Digital Equipment Corporation, GE FanucAutomation, Giddings and Lewis, Hewlett Packard, IBM, J ohnson Yokogawa, M oore Products, Siemens, SquareD Company, and TI Industrial Automation. Theserepresent the major PLC companies and some of the machine tool companies.

\section{Expert Systems}

Expert systems technology is a branch of artificial intelligence (AI) that uses computers to match or exceed the decisionmaking capability of human experts. Expert systems are useful to solve problems where nomathematical or algorithmic solution exists because data is inexact, uncertain, or based on probabilities.

Rule-based expert systems use groups of rules to perform consistent control actions. The system can monitor processes continuously to diagnose alarm conditions and prompt the operator on how to deal with them. An expert can automatically implement corrective action. 
Expert systems are appropriate when:

- The current methods are too slow, inaccurate, or inconsistent.

- The problem is small enough that it can be solved by a human expert in a matter of hours.

- A human expert exists.

- Only one or two experts exist when many are needed.

- There is an identifiable benefit.

A CERL study concluded that AI/expert systems technology is not yet economically practical for use in the operation and maintenance of theArmy's WWTPs (Kim et al. 1988). That study used a list processing (LISP)-based workstation and knowledge engineering environment (KEE) - a very powerful combination. A simpler approach could use a personal computer $(\mathrm{PC})$ and a rule-based expert system shell software package. An ideal applicati on would predict water plant flows to meet anticipated demand. This type of application may prove somewhat more economical.

\section{Statistical Process Control}

The use of control charts to distinguish between normal and abnormal operations is part of Statistical Process Control (SPC) or Statistical Quality Control (SQC). A control chart plots data over time with statistically determined upper and lower limits drawn on either side of the process average. Control charts hel p detect trends in operation. The upper and lower limits define the normal process variation. Variation results from many small causes including the capability of the process, clarity of operations procedures, etc.

Malfunctions or upsets usually show up as points outside the limits. Control charts can be used for monitoring so when something goes wrong it is immediately detected. Operators can take action before major permit violations occur. Although used extensively in manufacturing, SPC is infrequently used in water and wastewater applications. M ost PC-based operator display software includes an SPC capability as an option. 


\section{Available Control System and Instrumentation Options}

The application of SCADA in water systems has become moretheindustry standard as a result of the spatial extent of water distribution systems and the real-time need-to-know nature (for pressure distribution) of water systems control operations. The fol lowing sections discuss generic industry standards for automating water systems based on A\&E and consultants' wide range of experience with SCADA systems application. Wastewater operations can certainly follow the same guidelines, yet they currently lag behind the water operations example. Thefollowing scenario was built to illustrate SCADA applications for water systems automation and control.

\section{Treatment Plant Controls Overview}

The majority of a typical Army installation treatment plant's equipment is controlled with manually operated switches and push buttons. Most of the plant's controls are located on a central control panel located in the plant's main control room. Other panels may also be in the same control room. One of the main problems with the plant control equipment is the condition of the control panels and associated equipment in the control room. A freestanding control panel could typically have been designed originally to automatically control and monitor the plant filters, chemical feed, and high service pumps. Due to age and the unavailability of parts, large portions of these panels become inoperable. In particular, automatic control devices are the most susceptible portion of a typical early system failure.

Additional consideration should be given to the proximity of the control panels with respect to major system components. For example, a control panel's location in the control room could restrict the ability of an operator to visually monitor filter operation, particularly while backwashing.

\section{Distribution System and Booster Pump Control Overview}

A system of PLCs and radios can provide monitoring and control between pump stations and standpipes. A remote booster pump station PLC can communicate 
effectively by radio to a PLC in a control panel, located in the treatment plant control room. Yet, it is often hard to find replacement parts for certain PLCS because of the age of the equipment, and because they are nolonger manufactured. Users originally had no method of changing the programming or troubleshooting the software. The recent trend has been for the user community to obtain the programming software, but they still rely on outside assistance for some troubleshooting.

\section{Distribution System Elevated Tanks Monitoring Overview}

Tel ephone lines are used mostly to communi cate to water storage tanks. The telephonelines transmit a signal back to the plant or the nearest booster station, where it is displayed on indicators at the booster station and on chart recorders located in the treatment plant control room in municipal applications. Thetelephonelines for water storage tanks are normally leased and often make an installation dependent on an outside agency for maintenance and repair of its telemetry network. When the lines cross boundaries between two different telephone companies, it normally complicates matters, which inevitably means that neither company accepts responsibility for problems that occur.

\section{Well Field Control Overview}

If a plant's raw water is obtained from wells near the plant, a control system should be installed so that the operator can start and stop the pumps from the well control panel in the treatment plant control room. Current well field telemetry equipment normally uses radio communications to communicate between the treatment plant radio transmission unit (RTU) and the well RTUs. Radio interference problems have made the use of radios for communications less reliable. To replace radio communications, buried copper cables may be installed from the treatment plant control room directly to each well. Signals are directly connected between facilities rather than using RTU serial communications. For example, a contact doses at the RTU in the well control panel at the treatment plant; this contact closure is then detected by the RTU at the well to initiate starting the well pump. This control scheme does not, however, operate reliably due to potential problems with the underground cables or with unreliable electronic components. 


\section{Advanced Technologies for Control Systems Communication}

This chapter is a brief review of current main options for control system technologies. For each future automation area, several alternative control system approaches should be identified. Each alternative system should be gauged against a set consisting of: installation unique requirements, local environmental laws, and Army-wide procurement and implementation policies. Developing alternatives ahead of time will allow a much smoother and efficient SCADA system design.

\section{PLC/HMI System}

The PLC/Human-Machine Interface ( $\mathrm{HMI}$ ) system allows the user flexibility in hardware and software at a low cost. Generally, the same manufacturer does not provide the PLC and the HMI, although several manufacturers do offer both. Lower capital costs are initially achieved for procurement and installation when a single manufacturer is used. Separation of the PLC and HMI means the equipment and software are not fully coordinated by the manufacturers, so the user has a responsibility to initially program and maintain the system when separate manufacturers are used.

The PLC is programmed for field input/output (I/O) and control functions, whilethe $\mathrm{HMI}$ is programmed for the operator interface and database functions required for operations and reporting. Following is background information for both components of a PLC/HMI system.

A PLC is a field I/O interface device with a built-in processor for control programming. The PLC consists of standard, off-the-shelf hardware. The programming software is provided by the manufacturer or by a third-party supplier. Typical PLC vendors includeSiemens, Allen-Bradley, Modicon, and GE FanucAutomation. Programming for the PLC has typically been ladder logic programming (which resembles el ectrical schematic drawings). Most manufacturers now, however, offer software devel opment packages that include programming tools such as flowcharting, object programming, and visual basic programming. 
An $\mathrm{HMI}$ is a computer with graphics and control software used by plant operators to provide the control and monitoring functions of the control system. HMI hardware generally consists of a standard, off-the-shelf PC. Software can be provided by suppliers who specialize in HMI software, or by PLC manufacturers. The computer system is used to graphically represent the processes being monitored and controlled by the PLC system. Their popularity is attributable to the fact that the end user is not tied to a specific hardware manufacturer for the computer and to the ease-of-use and familiarity associated with PCs. The system also offers a level of security in operations with the control and operator interface physically separated between the PLC and the HMI.

The PLC/HMI-based control system will provide the foll owing desirablefeatures for an Army installation:

- Army operators have general familiarity and experience with the PLC system, which is an older application.

- Control functions are normally distributed throughout an operating plant, enhancing operational integrity.

- Control programming and operations in the PLC are segregated (i.e., removed from the HMI computers). Programming in the PLC separates the function of the control for the plant and the function of interface for the operators. It has been observed that operator interface units in a control room are more susceptible to restarting and human intervention with the programs.

- Some of the existing ladder logic control may be reusable.

- Local maintenance support is available from PLC vendors.

- Standard communications protocols have been developed for networks and PLCS.

- Computer equipment is available from several vendors.

Several PLC and HMI vendors are readily available to demonstrate their products to Directorate of Public Works (DPW) personnel, these manufacturers include (by category):

- HMI - Wonderware, Intellution, GE Fanuc, and Rockwell Software

- PLC - Allen Bradley and GE Fanuc.

\section{Communication Systems}

Within the water/wastewater industry, several communication options aretypically considered. Options explored include very high frequency (VHF) radio, ultra-high frequency (UHF) radio, multiple address system (MAS) radio, spread spectrum radio, and leased telephone lines. 


\section{VHF Radio}

VHF radio systems consist of radios broadcasting at an Federal Communications Commission (FCC)-licensed frequency between 150 and $170 \mathrm{MHz}$. These systems were very popular in the early days of remote data communication. They are generally systems that transmit and receive on the same frequency (single-frequency system).

Due to the popularity of this class of radio, a multitude of data and voice applications have been installed. This popularity has created interference concerns for data users. Local sanitation facilities often havea VHF frequency-based communication system between the water treatment plant and the well fields, but voice users sometime sever the link; therefore, it becomes subject to interference. The frequencies are generally available but probably not used.

\section{UHF Radio}

UHF radio systems consist of radios broadcasting at an FCC-licensed frequency be tween 450 and $470 \mathrm{MHz}$. They are generally single-frequency systems. This frequency band is allocated for land mobile use, which has created interference concerns for data users because users are not al ways in the samelocation. Frequency bands are generally useful for remote booster pump station communications and have proven effective for other similar operations.

\section{MAS Radio}

MAS radio systems consist of radios broadcasting on separate, FCC-licensed send and receive frequencies. Frequencies for these systems are generally $928 / 952 \mathrm{MHz}$. The FCC recently indicated it would make additional frequency pairs available at 932/941 M Hz because of the popularity of these types of radio systems.

One of the differences between the MAS and UHFNHF systems is that MAS systems are used for data exclusively (which makes them more predictable and detectable when exploring potential interference problems). MAS systems also have a lower power output limitation, which keeps them from overpowering one another.

\section{Spread Spectrum Radio}

Because of MAS system popularity, all available MAS frequencies in most large metropolitan areas have al ready been allocated. The growing popularity of using radio for data communications and the need for frequency "hopping" led to development of an unlicensed radio system called spread spectrum. 
Spread spectrum radio systems are actually the commercial implementation of declassified military radio system technol ogies. Spread spectrum radio systems "hop" from channel to channel over 240 channels that range from $902 \mathrm{MHz}$ to $928 \mathrm{MHz}$. By using a random hopping pattern, the likelihood of multiple users being on the same channel is minimized. An additional method of minimizing interference is to limit the transmit power. Spread spectrum radios are limited to 1 watt (as opposed to 5 watts for MAS systems). By limiting the transmit power, the range of each radio system is limited to about 5 miles.

\section{Leased Telephone Lines}

An installation could make use of leased telephone lines for communications between facilities. Leased telephone lines are similar to the dial-up type telephone circuits, except that the connection is continuous (i.e., no dialing is required). Various grades of circuits are available for data communications over leased tel ephone lines. For instance, the simplest grade line is used for telemetry communications, while a higher-grade line, called a conditioned line, would be used for communications between the remote PLCs and the control room. The conditioned telephone line is specially shielded to provide low noise for higher signal quality transmission.

It is possible that separate companies could provide telephone service for an area covering a large distribution system. Although multiple service does not generally present any difficulties, the lines that cross service areas could have problems with switching and availability. WherePLCs communicate over telephonelines to other PLCs throughout the system, use of conditioned leased tel ephonelines where available is advised. 


\section{Selecting SCADA Systems: Criteria and Approach}

When planning to install a SCADA system, whether new or as a replacement of a previous system, it is important to select the most appropriate system for the facilities. Though there area number of sources for information about SCADA systems, the many different types of systems available present a sizeable challenge to any personnel not regularly involved in SCADA application. It is, therefore, highly recommended that the detailed design and installation of a SCADA system be left to professionals with demonstrated design and installation experience.

The most important aspect of a successful SCADA system is not the detailed design, but the determination of the actual needs of the final user. No SCADA professional can determine these needs without the early involvement of the ultimate user in the SCADA development.

This section outlines the prel iminary work a facility operator (or even a SCADA professional) must do before shopping for a SCADA system (Wrzesi nski 2000). Taking these steps will ensure arriving at a system configuration that meets the facility needs while optimi zing both time and cost.

This approach is organized in a 10-question format, but is highly iterative. As the facility operator progresses through the steps, it is not unusual to further clarify a previous item. An experienced professional will address each of these items in some form, but doing the preliminary work in advance can greatly expedite the design process.

\section{What Do Similar Facilities Have?}

The best way for a facility operator to begin this process is to become familiar with the systems operating in his/her area. These existing systems will often vary from old to new and from simple to complex. 
Initiate the search by calling around and asking about other systems and their owners' experiences. Most of these owners are more than willing to discuss the pros and cons of their systems.

Ask if you can visit their site and observe the operation in person. Hands-on experience will allow you to test each system's capabilities. It is important to pay attention to the specific type of graphics, methods of conveying information to the operators (operators interface), and ease of use. Look at the telemetry methods and how they compare to those methods available to you. Actual operating experience often presents considerable information, and these owners and systems with an operating history can tell you more than any vendor's presentation. Making notes of the points you hear and observe will assist in defining your needs.

\section{Why Does My Installation Need SCADA?}

Contemplating your installation needs after conducting theinitial survey is thenext step. A list of needs for a proposed SCADA system may hel p justify the system with your installation commander. The list may include the need to improve the efficiency of your operation. I mprovement may include chemical storage, energy consumption, travel time, record keeping, etc.

The system may also be justifiable on the basis of modifying staff requirements. Modification can include staff reduction, job description revisions, and/or staff loss through attrition. Another need may beto resolve system problems. Development may require tighter pressure control, monitoring of remote facilities, or vandalism protection. A number of other mission-rel ated needs may be val id, but listing them clearly and coherently will ensure they are satisfied in the design.

\section{What Do You Want Your SCADA System To Do?}

The level of the functions you require defines the complexity of your SCADA system. A simple system may only monitor the status of facilities, and another level allows manual control from a central location. Increasingly complex levels include reporting via required forms and archiving of historical data. At thetop of the complexity level is full automation of operations. Determine the level you must have and what you may or may not wish to have in addition. As an example, automation may not be desired in a situation due to philosophy, union rules, or similar issues. 


\section{What Are Your System/Service Area Trends?}

The nature of the service area is important to SCADA design. Is the system expanding, stable, or is it shrinking in either surface area or demand patterns? Are the system facilities undergoing or soon to be upgraded, or are facilities pretty well stable in population and load fluctuation? Is your DPW assuming increased responsibility for sewage, maintenance, etc., from other departments dueto reorganization or downsizing, or is privatization a possibility? By being aware of the anticipated changes to the service area, the system can be designed with enough flexibility to remain viable through the anticipated changes.

\section{What Are Your Staff's Capabilities?}

All systems are operated by a varied mix of staff, each with a unique combination of skills, experiencelevels, and operating preferences. Theparticular skills of thestaff will dictate the initial and ultimate interfaces to the system, and ensure that successful system implementation is not hindered by less experienced staff.

If staff members are firmly establ ished and set in their operating philosophy, a multiple stage approach to system interface is often the best technique. This group typically desires hands on control, is reluctant to make rapid operati onal changes, and is often fearful of computer-like keyboards, screens, etc. A successful system for this group will often have local/manual control facilities, with selector switches, push buttons, indicator lights, and indicators in the form of either physical devices or animated icons on touchscreen-type panels. These allow the operators to control the system in a fashion similar to what they are used to, and to hopefully develop confidence in the system's reliability. As they grow comfortablewith thesystem operation, more sophisticated control methods using keyboards, function keys, computer mice, or other means can be introduced.

If your installation's system operating personnel are a more flexible mix of personnel, savings can be realized by designing a less basic form of local control/backup and immediately taking advantage of the efficiency of screens with keyboards and other interfaces. Involvement of the staff in the design will often result in a much faster and enthusiastic acceptance of the new system.

A note of warning should be given against the optimism and unrealistic expectations of "rocket scientist" type staff who feel all systems can be fully automated and controlled without local backup devices and someoperator involvement. Computers and SCADA do crash and, unless you can afford a "NASA" level of redundancy (and budget), it is not wise to put total trust in the system alone. 


\section{What Is Your Implementation Timetable?}

Do you have the funds and commitment to design and install this system immediately, or is a longer period and a phased approach more appropriate? If the anticipated period is between 2 and 5 years, it is reasonable to expect the system to go in without major redesign consideration. If the design and installation period is more than 5 years, you should allow for a review and possible redesign about every 3 years to ensure compliance with the latest standards.

\section{What Are Your Local Telemetry Options?}

A review of the communication links available will expedite design. If the plant is all on one site, or is interconnected by right-of-way accessible to you, a hardwire system of copper or fiber is possible. Off-site facilities can use telephone, cable TV, licensed radio, spread spectrum radio, or a mix of these. The best way to determine what is available in your area is to talk to others and find out what has or has not worked for them.

\section{What Are Your Budget and Expense Constraints?}

No system can be implemented without adequate resourcing, so the determination of how to justify the funds and how much of it should be allocated is an immediate consideration. The extremes range from the well-supported DPW operator who has his installation commander's backing to the less resourced operator who has to start from scratch for authorization and has a very tight budget. By now you should have some idea of the cost of your targeted system and, ther efore, have a more realistic idea about funds. Try to further define these constraints for upcoming reviews and budget drills.

\section{What Are Your Procurement Practices?}

The final document required to build the system must be defined prior to formal design. This may be as simpleas a Purchase Order; a negotiated price with a desired vendor; or a full open-bid set of plans and specifications. Armed with an adequate range of the proposed system cost, you can see if any local environmental laws and Army-wide policies governing procurement may apply in that pricerange. Knowing how the design end-product must be structured, proceed with the design. 


\section{How Do You Intend To Specify?}

The final question in this approach is how to design/specify the system. As you now have an idea of the magnitude of your system needs, do you havethetime and skills to develop it in-house with your installation staff? Except for very small projects, this route is not highly recommended.

If vendors/integrators are local and familiar to your installation needs and unique requirements, you may wish to discuss and devel op the system with thesefirms, at least initially. Care is required here as many vendors know their system, but know little about details like conduit, wiring, primary devices, codes, or other systems. They are also potentially biased since they do sell their own products.

A consultant experienced in the design of similar systems in your area is another possible sourceto consider. Consultants should be register ed professional engineers and can either design or design/build. They can provide the benefit of their experience in all aspects of the system, from hardware to software and programming. They may also be familiar with many different types of systems.

Contemporaries in your area have probably used several of the above methods. You should therefore include this question in your revisit of Step 1.

\section{Final Steps}

Once you go through the 10 steps, revisit some of them in an iterative mode. The proposed fine-tuning and repetition assures you that any loose ends will be reconsidered in light of later steps. Once you have been through this iterative approach, it will improve the project visibility, tighten the scope, and make more sense the second and third time around.

A qualified design professional should go through all these steps with you or with DPW staff who are knowledgeable of your installation needs. Being aware of your needs and alternatives ahead of time will result in a much smoother and efficient SCADA system design and final operating system. 


\section{Conclusions and Recommendations}

The Army should continue to modernize its facilities to both gain the economies of more efficient operation, and to better meet water and wastewater requirements. Automation of Army water and wastewater treatment plants may help the Army reduce costs and increase the operational effectiveness of existing staff in several ways. Where staff levels are bel ow minimum, automation can maximize the effectiveness of available personnel. At some facilities, staff could be re-deployed or reduced by using automation to eliminate off-shift staffing and to centralize and consolidate the operation of the water and wastewater systems. Appropriate off-theshelf technol ogies that can meet these needs are digital control systems based on: (1) SCADA systems, (2) PLCs, and (3) PCs. These technologies can be implemented where appropriate in water and wastewater applications. PLCs, for instance, are recommended for application in water plants and distribution systems, and wastewater collection systems and treatment plants. Single-loop controllers are recommended for use with smaller water and wastewater treatment plants.

Each treatment plant is unique, and each automation project must be properly engineered. Automation should focus on labor- and chemical-intensive processes. A phased approach to automation will al low plant staff to grow in knowledge and experience appropriate to their skills and capabilities. In general, it is recommended that each plant install a PC-based operator station with PLCs and interface to existing instruments and control equipment.

As plants are upgraded or equipment is replaced, plant maintenance personnel or contractors can use standards to automate the plant. Over time, more complex instruments can be added and additional processes can be automated. As installati ons upgrade their technologies, water and wastewater systems at each site will be designed for automation as a single project. Ensuring that automation equipment for the majority of projects is relatively similar, however, could reduce the overall Army's long-term operation and maintenance costs. 


\section{References}

Cited

Kim, Byung J . and Robert G. Skrentner, An Evaluation of Technol ogies To AutomateU.S. Army Water and Wastewater Systems, Technical Report (TR) EP-94/01/ADA277051 (U.S. Army Construction Engineering Research Laboratory [USACE RL], November 1993).

Kim, Byung J ., J ames E. Alleman, Chai S. Gee, and J ohn T. Bandy, Use of Programmable Logic Controllers To AutomateControl and Monitoring of U.S. Army Wastewater Treatment Systems, TR N-91/27/ADA241372 (USACERL, J uly 1991).

Kim, Byung J ., J ohn T. Bandy, K.K. Gidwani, and S.P. Shelton, Artificial Intelligence for U.S. Army Wastewater Treatment Plant Operati on and Maintenance, TR N-88/26/ADA200434 (USACERL, September 1988).

Skrentner, Robert G., I nstrumentation Handbook for Water and Wastewater Treatment Plants (Lewis Publishers, 1988).

Wrzesinski, Stephen A., Primer on SCADA System (CTE Engineers, Chicago, IL, J uly 2000).

\section{Uncited}

Black \& Veatch, Inc., City of St. Peters Report, Master Plan for Automation \& Control (Tampa, FL, J une 2000). 


\section{CERL Distribution}

Chief of Engineers

ATTN: CEHEC-IM-LH (2)

ATTN: CEMP-RI (2)

Engineer Research and Development Center (Libraries)

ATTN: ERDC, Vicksburg, MS

ATTN: Cold Regions Research, Hanover, NH

ATTN: Topographic Engineering Center, Alexandria, VA

Defense Tech Info Center 22304

ATTN: DTIC-O

8

$6 / 00$ 


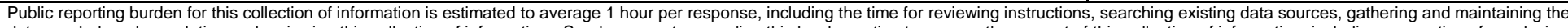

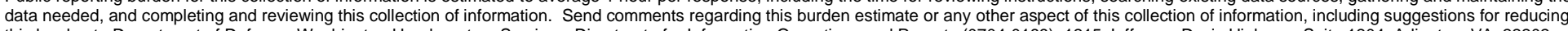

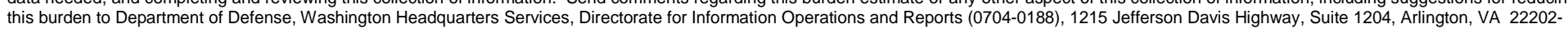

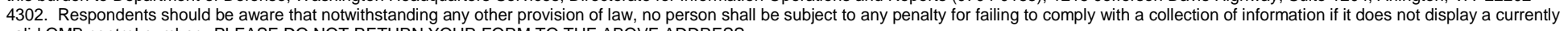
valid OMB control number. PLEASE DO NOT RETURN YOUR FORM TO THE ABOVE ADDRESS.
1. REPORT DATE (DD-MM-YYYY)
2. REPORT TYPE
$11-2001$
3. DATES COVERED (From - To)

4. TITLE AND SUBTITLE

Final

Assessment of SCADA Technology Applications To Automate U.S. Army Water and

Wastewater Sanitary Systems

5a. CONTRACT NUMBER

5b. GRANT NUMBER

5c. PROGRAM ELEMENT NUMBER

6. AUTHOR(S)

Richard J. Scholze and Hany H. Zaghloul

5d. PROJECT NUMBER

622720A896

5e. TASK NUMBER

5f. WORK UNIT NUMBER

TFO

8. PERFORMING ORGANIZATION REPORT NUMBER

ERDC/CERL TR-01-68

Construction Engineering Research Laboratory (CERL)

P.O. Box 9005

Champaign, IL 61826-9005

9. SPONSORING / MONITORING AGENCY NAME(S) AND ADDRESS(ES)

U.S. Army Corps of Engineers

441 G Street, NW.

Washington, DC 20314-1000

11. SPONSOR/MO
NUMBER(S)

\section{DISTRIBUTION / AVAILABILITY STATEMENT}

Approved for public release; distribution is unlimited.

\section{SUPPLEMENTARY NOTES}

Copies are available from the National Technical Information Service, 5285 Port Royal Road, Springfield, VA 22161.

\section{ABSTRACT}

The U.S. Army currently faces reductions in budget and personnel that support and operate its domestic water and wastewater systems. It may be possible to maintain required levels of service at Army sanitary facilities by installing and using automated systems at the plants. Automation technologies have been successfully applied at municipal and industrial water and wastewater treatment plants, and collection and distribution systems. The Army, however, has automated relatively few of its water and wastewater systems.

This report provides a state-of-the-art assessment for water and wastewater systems automation. In assessing currently available automation techniques for Army water and wastewater treatment plant operation and distribution/collection systems, the authors focused on 2-5 MGD (million gallons per day) plants (the most common range at the larger installations).

The content of this report was intended to build on a previous review of water/wastewater systems automation technologies and examine its applicability by a review of state-of-the-art technologies and their applicability to Army scenarios. This study investigated and evaluated the Army's needs to automate its water and wastewater systems using off-the-shelf technology. Several alternative control system approaches were identified and a general approach for selecting and specifying Supervisory Control and Data Acquisition (SCADA) systems was recommended.

\section{SUBJECT TERMS}

Army facilities, automation, Supervisory Control and Data Acquisition (SCADA), water distribution, wastewater treatment plants

\begin{tabular}{|l|l|l|}
\hline 16. SECURITY CLASSIFICATION OF: \\
\hline $\begin{array}{c}\text { a. REPORT } \\
\text { Unclassified }\end{array}$ & $\begin{array}{c}\text { b. ABSTRACT } \\
\text { Unclassified }\end{array}$ & $\begin{array}{c}\text { c. THIS PAGE } \\
\text { Unclassified }\end{array}$ \\
\hline
\end{tabular}

\begin{tabular}{|c|c|c|}
$\begin{array}{c}\text { 17. LIMITATION } \\
\text { OF ABSTRACT }\end{array}$ & $\begin{array}{c}\text { 18. NUMBER } \\
\text { OF PAGES }\end{array}$ & 19 \\
\cline { 3 - 3 } SAR & 30 & \\
\end{tabular}
19a. NAME OF RESPONSIBLE PERSON Richard J. Scholze 19b. TELEPHONE NUMBER (in- clude area code) (217)398-5590

